\title{
Tandem Mass Spectrometry of Small, Multiply Charged Oligonucleotides
}

\author{
Scott A. McLuckey, Gary J. Van Berkel, and Gary L. Glish \\ Analytical Chemistry Division, Oak Ridge National Laboratory, Oak Ridge, Tennessee, USA
}

\begin{abstract}
Multiply charged anions derived from electrospray ionization of the sodium salts of various small oligonucleotides $(n=4-8)$ have been subjected to tandem mass spectrometry (MS/MS) in a quadrupole ion trap. All ions were observed to dissociate with high efficiencies even under conditions not ordinarily conducive for the observance of high MS/MS efficiency. Large fractions of the total product ion signal could be attributed to single-cleavage reactions with the parent ion charge shared among the two product ions in various combinations. In every case, the most facile reaction was observed to be the loss of the adenine anion. This reaction was then observed to be followed by cleavage of the $3^{\prime}$ $\mathrm{C}-\mathrm{O}$ bond of phosphodiester linkage of the sugar from which the adenine had been lost. (J Am Soc Mass Spectrom 1992, 3, 60-70)
\end{abstract}

$\mathrm{F}$ ew ionization methods have proved to be useful for oligonucleotides. Until recently, successes have been restricted to plasma desorption [1-3] and negative ion fast atom bombardment [4-6]. Matrix-assisted laser desorption [7-9] and electrospray (ES) ionization [10-18], however, now provide alternatives for ionizing oligonucleotides. Electrospray, in particular, has shown dramatic success in ionizing oligonucleotides $[19,20]$ extending in size up to 76 residues [15]. Sodium salts of oligonucleotides, for example, give series of multiply charged anions under negative ion ES conditions of the form (M-nNa $\left.{ }^{n}\right)^{n-}$ and $\left(\mathrm{M}-\mathrm{nNa}^{+}+\mathrm{mH}^{+}\right)^{(n-m)-}$. The tendency for multiple charging provides the same advantages in the accurate determination of oligonucleotide molecular weight that has been demonstrated for peptides and proteins $[15,19]$. It has been pointed out, however, that anion signals from oligonucleotides tend to be lower than positive ion signals from peptides and proteins, which implies possibly lower sensitivities for oligonucleotides than for peptides and proteins, and that extensive incorporation of $\mathrm{Na}^{+}$in the anions can complicate molecular weight determination for high mass ions [15]. Significant challenges remain, therefore, in making ES ionization as useful for oligonucleotides as it has been shown to be for peptides and proteins.

Another challenge in maximizing the information obtainable from an oligonucleotide via ES ionization lies in the application of tandem mass spectrometry (MS/MS) to multiply charged anions. Structurally in-

Address reprint requests to Scott A. McLuckey, Analytical Chemistry Division, Oak Ridge National Laboratory, P.O. Box 2008, Oak Ridge, TN 37831-6365. formative fragmentation has been shown to occur for a wide variety of multiply protonated peptides and proteins [15]. The determination of product ion charge states often poses problems in interpreting MS/MS spectra, however, particularly when both product ions from a dissociation are not apparent in the spectrum, as is often the case with peptides and proteins [15]. This problem is being approached both by use of high resolving power $[21,22]$ and ion/molecule reactions [23]. We are aware of no MS/MS data published for multiply charged oligonucleotide anions, although preliminary experiments have been briefly described [20]. In fact, relatively few MS/MS data have been reported for singly charged oligonucleotides of $n \geq 2$ $[8,24-31]$. We have therefore studied the behavior of several multiply charged oligonucleotides from $n=$ 4-8 with a quadrupole ion trap to determine their behavior under ion trap collisional activation conditions. In particular, we were interested in the structural information inherent in the dissociation of the multiply charged anions, the appearance, or lack thereof, of both products from a dissociation, and the MS/MS efficiency. These characteristics are all important in determining the analytical applicability of MS/MS to oligonucleotides ionized by ES. The relatively small oligonucleotides that are the subjects of this work provide simple systems to study and the results should prove helpful in interpreting data derived from MS/MS of larger oligonucleotides.

\section{Experimental Section}

All experiments were performed with a Finnigan-MAT (San Jose, CA) ion trap mass spectrometer (ITMS) $\left(r_{0}=1.0 \mathrm{~cm}, \Omega / 2 \pi=1.1 \mathrm{MHz}\right)$ modified to allow 
ions formed external to the ion trap to be injected [32]. Details of the instrument as it is used to perform experiments with ES ionization have been reported $[33,34]$. Briefly, the ES "interface" is the hardware of an atmospheric sampling glow discharge ionization source [35], which consists of two in-line apertures of $100 \mu \mathrm{m}$ and $800 \mu \mathrm{m}$ in diameter, respectively, separated by $1.9 \mathrm{~cm}$. The $100-\mu \mathrm{m}$ aperture admits atmospheric gases along with ions formed by ES into the interaperture region, which is maintained at a pressure of 0.3 torr. Ions that pass through the interaperture region enter the vacuum system of the ion trap via the 800- $\mu \mathrm{m}$ aperture. A three-element lens system is used to focus ions that exit the $800-\mu \mathrm{m}$ aperture onto a hole in the "ion entrance" end-cap. The central lens element of the three-element lens system consists of two half-plates that are held at the same potential during the "ion injection" period. During the portion of the ion trap experiment wherein ions are mass-selected, collisionally activated, and mass analyzed, ions are prevented from entering the ion trap by biasing one of the half-plates of the central lens element such that ions are deflected from the hole in the ion entrance end-cap. Ion injection periods of $0.2-0.3 \mathrm{~s}$ were used for all experiments and the amplitude of the radiofrequency ( $\mathrm{rf}$ ) signal applied to the ring electrode during the injection period was 980 V 0-p.

Mass spectra and the final scan of an MS/MS or $\mathrm{MS}^{n}$ experiment were acquired by scanning the amplitude of the voltage applied to the ring electrode while applying a supplementary $\mathrm{rf}$ to the end-caps. This mode of operation is referred to as the massselective instability mode of operation [36] in conjunction with "axial modulation" [37]. In a few cases, the mass range of the instrument was extended from $\mathrm{m} / \mathrm{z}$ 650 to $\mathrm{m} / \mathrm{z} 1300$ by use of the "resonance ejection" technique [37, 38] to identify any product ions of $m / z>650$. This was done in those cases in which one or more product ions observed at $m / z<650$ would be expected to have a complementary product ion of $m / z>650$. A single ion isolation step was used for MS/MS experiments, and $n-1$ ion isolation steps were used for MS $^{n}$ experiments. Each ion isolation step consisted of two consecutive resonant ejection scans each involving a scan of the ring electrode if amplitude combined with the application of a supplementary rf signal to the end-caps [39]. The frequency of the supplementary if signal and the scan range of the ring electrode if amplitude were chosen in the first resonant ejection period to eject ions of mass-to-charge ratio less than that of the parent ion. These parameters were modified in the second resonant ejection period to eject ions exceeding the parent ion in massto-charge ratio by up to 500 . Mass-selected ions were subjected to collisional activation in the ion trap by applying a supplementary $\mathrm{rf}$ signal to the end-caps to match a fundamental secular frequency of the parent ion [40]. The supplementary field was created by applying equal frequency sine waves to each end-cap $180^{\circ}$ out of phase to provide an amplitude of $0.5-2 \mathrm{~V}$ p-p. Collisional activation periods typically ranged from 10 to $20 \mathrm{~ms}$ and the Mathieu parameter $q_{z}$ [41] for the ion to be activated ranged from 0.17 to 0.07 . Typical collisional activation experiments in the quadrupole ion trap employ $q_{z}$ values in the range of 0.2-0.4 to optimize MS/MS efficiency [40]. The parent ion $q_{z}$ value is important in collisional activation in that it determines the upper limit to kinetic energy of the parent ion before it is ejected from the ion trap. It also determines the low mass-to-charge ratio cutoff of the MS/MS experiment. The low mass-to-charge ratio cutoff increases with $q_{z}$ of the parent ion and the upper limit to kinetic energy increases with the square of $q_{z}$. Relatively low $q_{z}$ values were used in this work to allow for trapping of negatively charged bases from the oligonucleotide anions if they were formed from collision-induced dissociation (CID). Despite the use of relatively low $q_{z}$ values during collisional activation, MS/MS efficiencies were observed to be relatively high (see below). Mass spectra and MS/MS spectra shown herein are the average of 25-50 scans with each scan requiring $0.27-0.4 \mathrm{~s}$.

Means for automatically calibrating the mass scale provided by the ITMS data system are not available for negative ions using either axial modulation or resonance ejection. In the case of axial modulation, we use negative ion mass spectra acquired with atmospheric sampling glow discharge ionization [25] to establish a correction for the mass scale provided by the data system up to $m / z$ 400. In those cases in which resonance ejection was used to extend the mass range for an MS/MS experiment, we used the resonance ejection ES mass spectra of the oligonucleotide to determine a correction for the data system mass scale, the mass-to-charge ratio values of the ions in the mass spectra having already been established in an axial modulation scan.

One "absorbance unit" of each oligonucleotide was obtained commercially [ $5^{\prime}-\mathrm{d}\left(\right.$ ATGUAT) $-3^{\prime}$ from Pharmacia, Uppsala, Sweden, and all others from Sigma Chemical Co., St. Louis, MO] and each was supplied as the sodium salt. In each case, the entire sample was dissolved in a solution comprising high performance liquid chromatography (HPLC)-grade methanol and water $(9: 1 \mathrm{vol} / \mathrm{vol})$. The resulting solution concentrations for the tetramer and the octamers fell within the range of $40-100 \mathrm{fmol} / \mu \mathrm{L}$ and the solution concentration for the hexamer was $2 \mathrm{pmol} / \mu \mathrm{L}$. All sample solutions were subjected to ES at $1 \mu \mathrm{L} / \mathrm{min}$ with the ES capillary needle held at ${ }^{-} 3000$ to ${ }^{-} 3500 \mathrm{~V}$. It was noted from preliminary work that analyte signals tended to disappear within a period of a few days from the time the solutions were prepared for $E S$. This may be due either to analyte degradation or to adsorbance on the glass surface of the vial or to both. Data for each sample solution were, therefore, acquired in a single day and were repeated the next 
day. Beyond two days signal levels became too low to give reliable MS/MS and MS ${ }^{n}$ data.

\section{Results and Discussion}

A variety of parent and product ions can be observed in the ES MS/MS study of even a single oligonucleotide. The parent ion and product ion nomenclature used herein are therefore summarized below. All of the compounds used in this study were supplied as the sodium salts. The maximum charge state for anions from any of these compounds is equal to the number of phosphodiester bridges, or one less than the number of bases in the chain. The ion derived for a 4-mer with all sodium ions removed and without any protonated phosphodiester groups is therefore indicated herein as $\left(\mathrm{M}-3 \mathrm{Na}^{+}\right)^{3}$. Some sodium ions are often retained and some exchange of protons for sodium ions occurs in solution, resulting in various charge states and mixtures of cation combinations at some charge states. For example, a dianion from a sodium salt of a tetranucleotide might be $\left(\mathrm{M}-2 \mathrm{Na}^{+}\right)^{2-}$ or $\left(\mathrm{M}-3 \mathrm{Na}^{+}+\mathrm{H}^{+}\right)^{2-}$.

In contrast to the relatively simple nomenclature for ions observed in the ES mass spectra, nomenclature for the product ions observed in MS/MS and MS $^{n}$ spectra must be more complex owing to the wider variety of possible ions. We found that the nomenclature schemes proposed for MS/MS of (M$\mathrm{H})^{-}$oligonucleotide ions $[3,24]$ could not fully account for all of the product ions in the MS/MS spectra of the multiply charged oligonucleotides observed in this work. We therefore propose another scheme which is analogous to the nomenclature scheme now widely used for peptides and proteins [42]. This nomenclature is illustrated in Scheme I with a triply charged tetranucleotide with bases $B_{1}-B_{4}$. The four possible cleavages along the phosphodiester chain are indicated by the lower case letters $a, b, c$, and $d$ for fragments containing the $5^{\prime}-\mathrm{OH}$ group and $w, x, y$, and $z$ for fragments containing the $3^{r}-O H$ group. The numerical subscripts indicate the number of bases from the respective termini. Upper case B denotes a base with the numerical subscript indicating its position in the sequence beginning with the $5^{\prime}$ end of the chain.

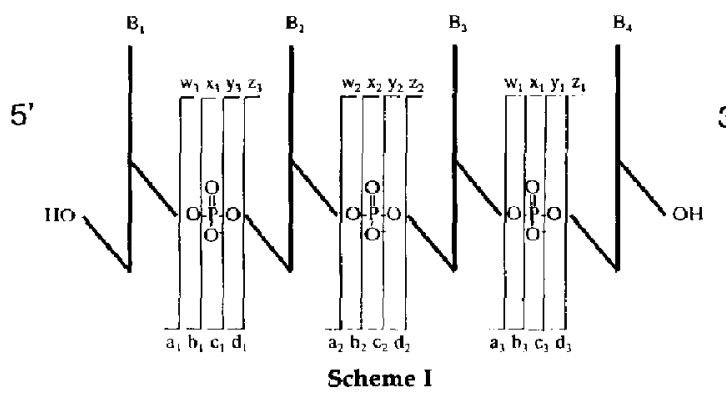

Lower case letters are used for the cleavages along the chain to avoid confusion with the abbreviations for adenine (A) and cytidine (C) and for the generic abbreviation for the base used here $\left(B_{n}\right)$. The specific base that is lost is indicated parenthetically along with the relevant $B_{n}$ designation, e.g., $B_{1}(A)$.

\section{$5^{\prime}-d(A A A A)-3^{\prime \prime}$}

The tetranucleotide d(AAAA) would, in some respects, appear to be uninteresting but the results for this compound are related here both to illustrate the nomenclature and to introduce several general observations regarding the behavior of all of the multiply charged oligonucleotides that we have examined to date. Figure 1 gives the ES mass spectrum of $\mathrm{d}(\mathrm{AAAA})$, which shows the $\left(\mathrm{M}-3 \mathrm{Na}^{+}\right)^{3-}$ anion $(\mathrm{m} / \mathrm{z}$ 395.7) and the two dianions $\left(\mathrm{M}-3 \mathrm{Na}^{+}+\mathrm{H}^{+}\right)^{2-}$ and $\left(\mathrm{M}-2 \mathrm{Na}^{+}\right)^{2-}$. No singly charged ions could be clearly discerned from the background. This spectrum is typical of the ES mass spectra of oligonucleotides that we have observed in that a single peak is observed for the highest possible charge state, as expected, and mixtures of cation combinations are observed at all lower charge states. Furthermore, the signal levels observed for the oligonucleotide anions are generally two orders of magnitude lower than those we typically observe for peptides and proteins in the positive ion mode. However, the estimated solution concentrations were also several orders of magnitude lower than those we normally use for ES of peptides and proteins. The mass spectra and MS/MS spectra of the oligonucleotides averaged over $20-50$ scans, therefore, show poorer signal-to-noise ratio than typical spectra acquired from peptides and proteins averaged over the same number of scans. For these studies, therefore, $\mathrm{MS}^{n}$ experiments were limited to $n \leq 3$. $\mathrm{MS}^{4}$ spectra could be acquired in some cases but, in general, third-generation product ions could not be

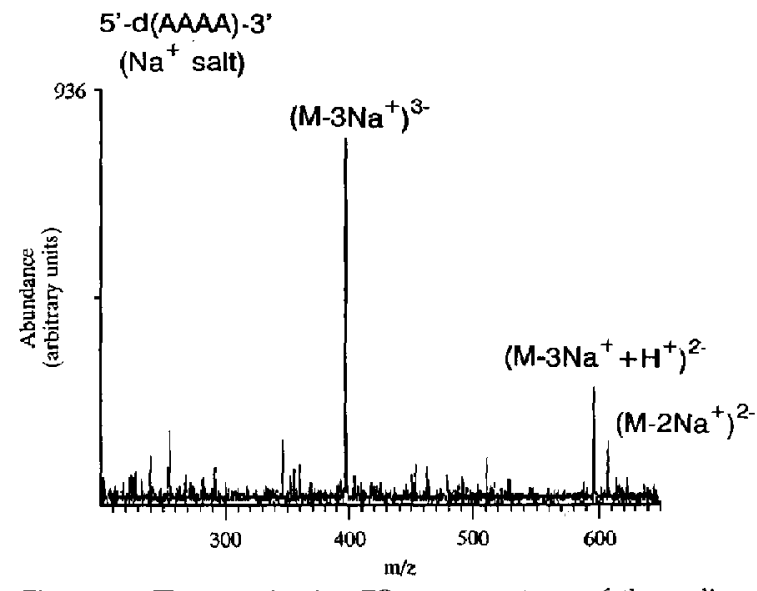

Figure 1. The negative ion ES mass spectrum of the sodium salt of $5^{\prime}$-d(AAAA)-3' 
reliably distinguished from background noise without averaging over 100 scans.

Figure 2a shows the MS/MS spectrum of the (M$\left.3 \mathrm{Na}^{+}\right)^{3-}$ parent ion using a relatively low supplementary of amplitude ( $800 \mathrm{mV}$ p-p). At this level much of the parent ion signal remains after the collision activation period. The major product ions in the spectrum are observed at $\mathrm{m} / z 134$ and $\mathrm{m} / z$ 526.5. The 2:1 ratio in the differences in the mass-to-charge ratio values of the product ions from that of the parent ion $(\mathrm{m} / \mathrm{z}$ 395.7) suggests that these ions are both formed from the same dissociation and that the $\mathrm{m} / z 526.5$ ion carries twice the charge as the $m / z 134$ ion. This conclusion follows from the conservation of mass and charge. If the two product ions are formed in the same dissociation and they are the only fragments formed in the dissociation, the mass balance for the
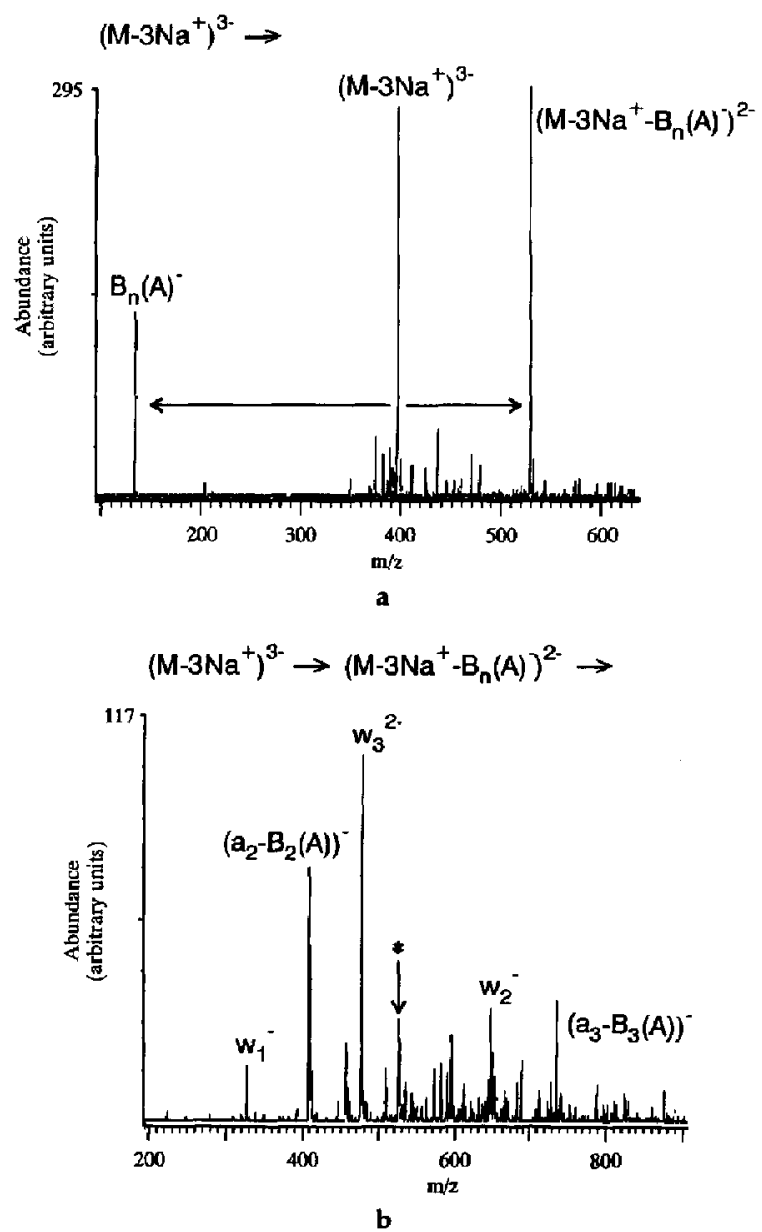

Figure 2. (a) The MS/MS spectrum of $\left(\mathrm{M}-3 \mathrm{Na}^{+}\right)^{3-}$ of $5^{\prime}-$ $\mathrm{d}(\mathrm{AAAA})-3^{\prime}$ and (b) the $\mathrm{MS}^{3}$ spectrum from the sequence (M$\left.3 \mathrm{Na}^{+}\right)^{3-} \rightarrow\left[\left(\mathrm{M}-3 \mathrm{Na}{ }^{+}\right)-\mathrm{B}_{n}(\mathrm{~A})^{-}\right]^{2-} \rightarrow$. The asterisk in $\mathbf{b}$ indicates the position in mass-to-charge ratio of the collisionally activated ion, $\left(\mathrm{M}-3 \mathrm{Na}^{+}-\mathrm{B}_{n}(\mathrm{~A})^{-}\right)^{2-}$. reaction is

$$
134\left(z_{p 1}\right)+526.5\left(z_{p 2}\right)=395.7\left(z_{P}\right)
$$

where $z_{p 1}$ and $z_{p 2}$ are the unit charges of the product ions and $z_{p}$ is that of the parent ion. Charge balance is given by

$$
z_{p 1}+z_{p 2}=z_{P}
$$

Substituting for $z_{P}$ in eq 1 and rearranging gives

$$
(395.7-134) /(526.5-395.7)=2=z_{p 2} / z_{p 1}
$$

For this specific case, therefore, the product ions almost certainly correspond to a negatively charged adenine $(\mathrm{m} / \mathrm{z} 134)$ and the doubly charged ion formed from loss of negatively charged adenine. According to the proposed nomenclature, these product ions would be labeled $\mathrm{B}_{n}(\mathrm{~A})^{-}$and $\left(\mathrm{M}-3 \mathrm{Na}^{+}-\mathrm{B}_{n}(\mathrm{~A})^{-}\right)^{2-}$, respectively. No particular subscript is assigned to the base because it could be lost from any position along the chain.

Figure $2 b$, which shows the $\mathrm{MS}^{3}$ spectrum resulting from the experimental sequence $\left(\mathrm{M}-3 \mathrm{Na}^{+}\right)(\mathrm{m} / \mathrm{z}$

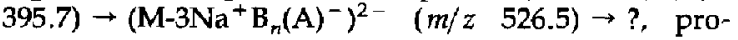
vides some information on the structures of the ions formed from loss of adenine. Because the first-generation product ions are doubly charged, second-generation products that are equidistant in mass-to-charge ratio from that of the first-generation product are likely to be formed from the same dissociation, viz. they are complementary ions. Two sets of complementary ions were consistently observed in acquiring these data. However, the ion that gives rise to the largest peak in the spectrum, which falls at $\mathrm{m} / z$ 476.5, does not appear to have a complementary ion. Either the complementary ion is not observed, due to further fragmentation or to some instrumental discrimination effect, or this second-generation product ion is doubly charged with the complementary product being neutral. The latter situation seems most likely here because $\mathrm{m} / \mathrm{z} 476.5$ is the expected value for the loss of a sugar with both charges remaining on the larger fragment. This can only occur if the missing adenine came from one end of the ends of the chain. The second. generation product ion would therefore be labeled either $w_{3}^{2-}$, if the adenine was lost from the $5^{\prime}-\mathrm{OH}$ terminus, or $\mathrm{d}_{3}^{2-}$, if the adenine was lost from the 3'-OH terminus (see Scheme II). No further conclusions can be drawn from these data alone. However, the data from the eight-member oligonucleotide isomers, as described below, indicated that there is a very strong tendency for cleavage at the $3^{\prime} \mathrm{C}-\mathrm{O}$ bond, as opposed to the $5^{\prime} \mathrm{C}-\mathrm{O}$ bond, of the sugar from which adenine has been lost. This observation would therefore suggest that the ion observed at $\mathrm{m} / \mathrm{z}$ 476.5 in the $\mathrm{MS}^{3}$ experiment is primarily $\mathrm{w}_{3}^{2-}$. 


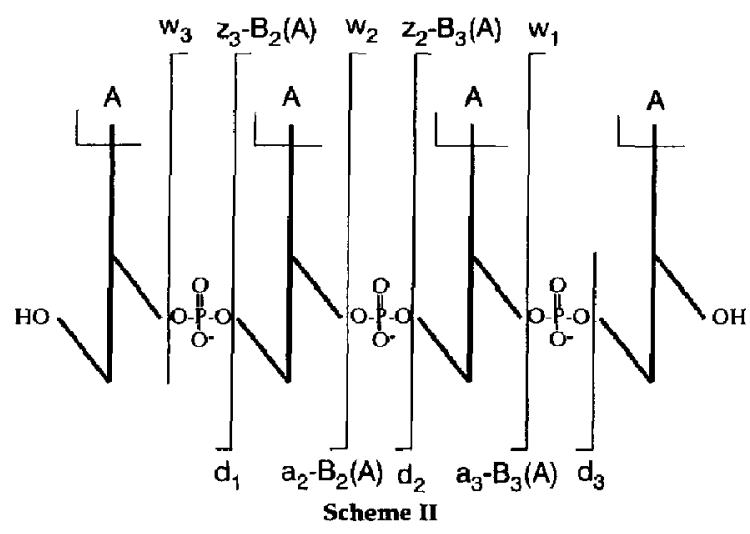

The two sets of complementary ions appear at values $m / z 412$ and 641 , and values $m / z 329$ and 724 . Once again, cleavages at two different sites can account for each complementary pair. The $412 / 641$ pair could be either the products $\left(a_{2}-B_{2}(A)\right)^{-}(m / z 412)$ and $w_{2}^{-}(m / z 641)$ or $\left(z_{2}-B_{3}(A)\right)^{-}$and $d_{2}^{-}$or a mixture of both. The $329 / 724$ pair could be either the products $\mathrm{d}_{1}^{-}(m / z 329)$ and $\left(\mathrm{z}_{3}-\mathrm{B}_{2}(\mathrm{~A})\right)^{-}\left(m / z\right.$ 724) or $\mathrm{w}_{1}^{-}$and $\left(a_{3}-B_{3}(A)\right)^{-}$or a mixture of both. The tendency for cleavage at the $3^{\prime} \mathrm{C}-\mathrm{O}$ of the sugar that loses an adenine alluded to above and demonstrated below suggests that the complementary pairs are primarily composed of $\left(\mathrm{a}_{2}-\mathrm{B}_{2}(\mathrm{~A})\right)^{-}$and $w_{2}^{-}$for the $412 / 641$ pair and $w_{1}^{-}$and $\left(a_{3}-B_{3}(A)\right)^{-}$for the $329 / 724$ pair.

It is apparent that much structurally significant dissociation is observed in the $\mathrm{MS}^{3}$ analysis of the $\left(\mathrm{M}-3 \mathrm{Na}^{+}\right)^{3-}$ anion from $\mathrm{d}(\mathrm{AAAA})$, Cleavage is observed at each phosphodiester linkage in the chain. Furthermore, the first cleavage clearly indicates the presence of adenosine in the oligonucleotide. Interestingly, these dissociations constitute $>80 \%$ of the total. It is also noteworthy that this information can be obtained from the fairly weak signals apparent in the mass spectrum. Parent ion signals tended to vary over factors of 2-5 from scan to scan in these experiments. Such parent ion signal variation makes difficult the accurate measurement of MS/MS efficiency. However, the MS/MS efficiency, defined as the total product ion signal divided by the difference in parent ion signals before and after collisional activation, was consistently 50\%-150\%. An MS/MS efficiency $>100 \%$ using the conventional definition results from the fact that two or more discrete ions may be produced upon dissociation of the parent ion and that the detection system is insensitive to charge. The total ion signal is dependent upon the total number of discrete ions and not on the total charge of the system. The important conclusion here is that the multiply charged oligonucleotides dissociate with high efficiencies under ion trap collision-induced dissociation (CID) conditions even when relatively low $q_{z}$ values are used during the collisional activation step. It is desirable to use low $q_{z}$ values during collisional activation to trap low mass product ions, such as the adenine anion, to facilitate the assignment of charge to larger product ions.

A final noteworthy observation in the MS/MS analysis of $\left(\mathrm{M}-3 \mathrm{Na}^{+}\right)^{3-}$ involves the dependence of the MS/MS spectra upon the amplitude of the supplementary rf signal applied to the end-caps. As the amplitude of this signal increases, the (M-3Na ${ }^{+}$ $\left.B_{n}(A)^{-}\right)^{2-}$ ion increasingly dissociates to give as products the ions observed as second-generation products in the $\mathrm{MS}^{3}$ spectrum of Figure $2 \mathrm{~b}$. This observation indicates that all of the structurally informative dissociation noted in the $\mathrm{MS}^{3}$ analysis using gentle collisional activation conditions can appear in the MS/MS spectrum under more violent conditions. At supplementary rf amplitudes $>2 \mathrm{~V}$ p-p, the $\left(\mathrm{M}-3 \mathrm{Na}^{+}-\right.$ $\left.\mathrm{B}_{n}(\mathrm{~A})^{-}\right)^{2-}$ dianion was barely apparent in the MS/MS spectrum because it dissociated almost quantitatively to give product ions from sequential fragmentations. Unless such a situation is recognized, the resulting spectrum can be difficult to interpret because the mass-to-charge ratio values of the product ions arising from consecutive dissociations bear no simple relationship with the parent ion mass-to-charge ratio. The $\mathrm{MS}^{n}$ approach using gentle collisional activation conditions would seem to be clearly desirable in that the product ion genealogy is more clearly defined.

\section{$5^{\prime}-d(A T G U A T)-3^{\prime}$}

Figure 3 shows the major ions observed in the ES mass spectrum of the sodium salt of the synthetic hexamer d(ATGUAT). As expected, a single ion, (M$\left.5 \mathrm{Na}^{+}\right)^{5-}$, is observed at the maximum charge state

$$
\begin{gathered}
\text { 5'-d(ATGUAT) }-3^{\prime} \\
\left(\mathrm{Na}^{+} \text {salt }\right)
\end{gathered}
$$

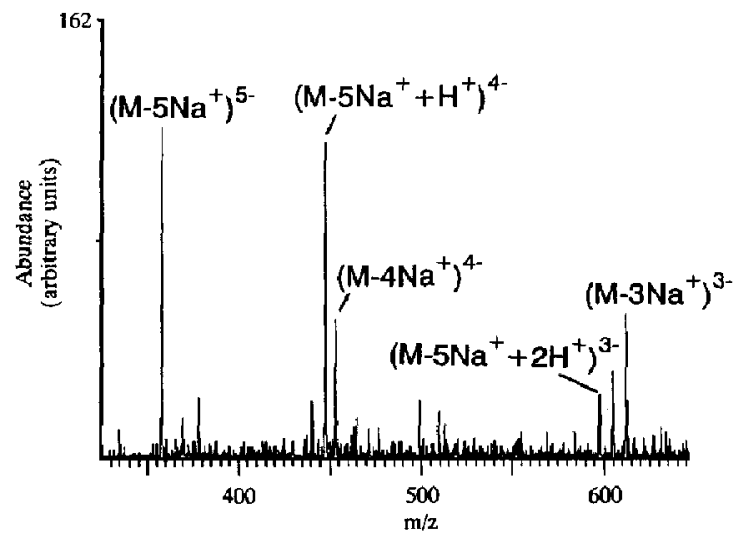

Figure 3. The negative ion ES mass spectrum of the sodium salt of $5^{r}$-d(ATGUAT) $-3^{\prime}$. 
and mixtures of ions with various combinations of $\mathrm{Na}^{+}$and $\mathrm{H}^{+}$are observed at the lower charge states. The $\left(\mathrm{M}-5 \mathrm{Na}^{+}\right)^{5-}$ ion $(\mathrm{m} / \mathrm{z}$ 357.4) was subjected to MS/MS using a low amplitude supplementary rf signal to give the MS/MS spectrum of Figure $4 a$. The ion was seen to dissociate with high efficiency (roughly $100 \%$ ) with virtually all of the fragmentation channeled into the loss of the adenine anion. Interestingly, no other base losses are clearly apparent in the spectrum. The complementary ion at $m / z 413$ constitutes the base peak in the spectrum. Because there are two adenosines in the sequence, the identities of these product ions could be $B_{1}(A)^{-}$or $B_{5}(A)^{-}$or a mixture
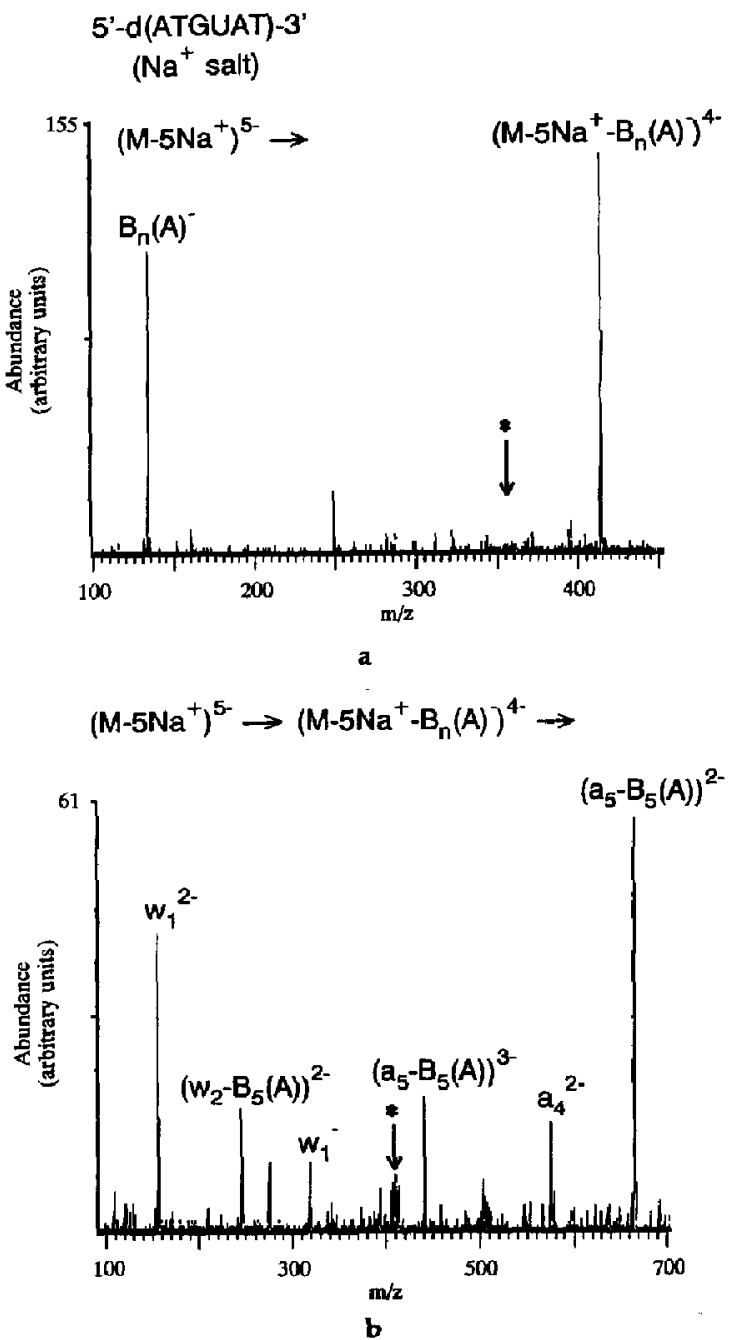

Figure 4. (a) The MS/MS spectrum of $\left(\mathrm{M}^{-5 \mathrm{Na}^{+}}\right)^{5-}$ of $5^{\prime}$ $\mathrm{d}(\mathrm{ATGUAT})-3^{\prime}$ and (b) the $M S^{3}$ spectrum from the sequence $\left(\mathrm{M}-5 \mathrm{Na}^{+}\right)^{5-} \rightarrow\left[\left(\mathrm{M}-5 \mathrm{Na}^{+}\right)-\mathrm{B}_{n}(\mathrm{~A})^{-}\right]^{4-} \rightarrow$. The asterisk indicates the position in mass-to-charge ratio of the collisionally activated ion. of both for the adenine anion and (M-5Na $\left.{ }^{+}-\mathrm{B}_{1}(\mathrm{~A})^{-}\right)^{4-}$ or $\left(\mathrm{M}-5 \mathrm{Na}^{+}-\mathrm{B}_{5}(\mathrm{~A})^{-}\right)^{4-}$ or a mixture of both for the corresponding complementary ion.

The major ions observed in the $\mathrm{MS}^{3}$ spectrum resulting from consecutive $\mathrm{CID}$ steps $\left(\mathrm{M}-5 \mathrm{Na}^{+}\right)^{5-} \rightarrow$ $\left(\mathrm{M}-5 \mathrm{Na}^{+}-\mathrm{B}_{n}(\mathrm{~A})^{-}\right)^{4-} \rightarrow$ ?, shown in Figure $4 \mathrm{~b}$, comprise three sets of complementary ions. Second-generation product ions equidistant in mass-to-charge ratio from that of the quadruply charged first-generation product ion are likely to be complementary ions and, if so, both are doubly charged. Second-generation product ions with a ratio of $3: 1$ in their differences in mass-tocharge ratio from that of the furst-generation product ion may also be complementary and, if so, the charges are one and three. Two sets of complementary ions appear to arise from cleavage at the same bond, differing only in the distribution of charge among the products. The most intense set of ions corresponds to the products $w_{1}^{2-}(m / z 160)$ and $\left(a_{5}-B_{n}(A)^{-}\right)^{2-}(m / z$ 666). The ions $w_{1}^{-}(m / z \quad 320)$ and $\left(a_{5}-B_{n}(A)^{-}\right)^{3-}$ $(m / z$ 444) also appear as a complementary pair. The masses of these products would be expected regardless of which adenine was lost. However, in light of the tendency for cleavage at the 3 ' $\mathrm{C}-\mathrm{O}$ bond from the sugar that loses an adenine (see below), it seems likely that most of the $m / z 666$ and $m / z 444$ secondgeneration product ions are $\left(a_{5}-B_{5}(A)^{-}\right)^{2-}$ and $\left(a_{5}\right.$ $\left.B_{5}(A)^{-}\right)^{3-}$, respectively. The first-generation product ion expected to give rise to these ions is $\left(\mathrm{M}-5 \mathrm{Na}^{+}\right.$. $\left.B_{5}(A)^{-}\right)^{4-}$. The isomeric anion $\left(\mathrm{M}-5 \mathrm{Na}^{+}-\mathrm{B}_{1}(\mathrm{~A})^{-}\right)^{4-}$ would be expected to lose a sugar (loss of $100 \mathrm{u}$ ) to give a quadruply charged second-generation product ion at $m / z$ 388, which is not observed in the $\mathrm{MS}^{3}$ spectrum. This ion may actually be formed and fragment further under the collisional activation conditions used here. However, this can only be a minor reaction channel because most of the second-generation parent ion charge can be accounted for in the $\mathrm{MS}^{3}$ spectrum.

The ions at $m / z 249$ and $m / z 577$ are also likely to be a complementary pair and, if so, both are doubly charged. Two cleavages can possibly give rise to these ions. If the first-generation product ion is $\left(\mathrm{M}-5 \mathrm{Na}^{+}\right.$$\left.\mathrm{B}_{1}(\mathrm{~A})^{-}\right)^{4-}$, the $m / z 249$ ion is $\left(\mathrm{d}_{2}-\mathrm{B}_{1}(\mathrm{~A})\right)^{2-}$ and the $m / z 577$ ion is $z_{4}^{2-}$. If the first-generation product ion is $\left(\mathrm{M}-5 \mathrm{Na} a^{+}-\mathrm{B}_{5}(\mathrm{~A})^{-}\right)^{4-}$, these ions are $\left(\mathrm{w}_{2}-\mathrm{B}_{5}(\mathrm{~A})\right)^{2-}$ and $a_{4}^{2-}$. Neither possibility can be discounted. However, for the reasons discussed above, it appears that most of the first-generation product ions were formed by loss of $B_{5}(A)^{-}$, which suggests that the latter assignments probably characterize most of the ions of this complementary pair. See Scheme III for the proposed cleavages.

Many of the observations made with the (M$\left.5 \mathrm{Na}^{+}\right)^{5-}$ ions from the sodium salt of d(ATGUAT) are reminiscent of those noted for the $\left(\mathrm{M}-3 \mathrm{Na}^{+}\right)^{3-}$ ions from the sodium salt of d(AAAA). For example, high MS/MS efficiencies were observed in spite of the use 


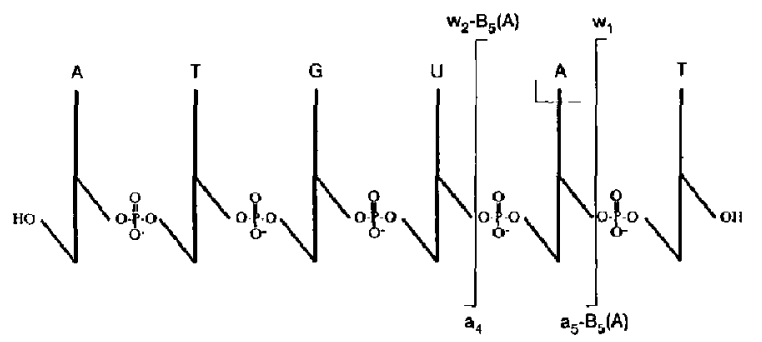

Scheme III

of relatively low $q_{z}$ values during collisional activation. The most intense product ions in both cases arise from the loss of an adenine anion. Dissociation of the ion formed by loss of an adenine anion, either by $\mathrm{MS}^{3}$ or by MS/MS using a relatively high supplementary if amplitude to induce consecutive fragmentation, gives sequence-specific ions. Most of the product ion signal is composed of complementary ions, which greatly simplifies interpretation. However, the anions from d(ATGUAT) did not show cleavage at every phosphodiester linkage in the $\mathrm{MS}^{3}$ spectrum.

\section{$5^{\prime}-d(C G G A T C C G)-3^{\prime}, 5^{\prime}-d(G T G G C C A C)-3^{\prime}, 5^{\prime}-$ $d$ (GGACGTCC)-3'}

The ambiguity in interpreting the MS/MS and MS" data for d(AAAA) and d(ATGUAT) due to the presence of two or more adenosines is absent in the MS/MS and MS ${ }^{n}$ analysis of the sodium salts of the isomeric octamers d(CGGATCCG), d(GTGGCCAC), and $\mathrm{d}$ (GGACGTCC). All three isomers gave very similar ES mass spectra in terms of relative and absolute abundances of ions in the various charge states when electrosprayed under the same conditions. Figure 5, which shows the ES mass spectrum of d(GTGGC-

\section{5'-d(GTGGCCAC)-3' ( $\mathrm{Na}^{+}$salt)}

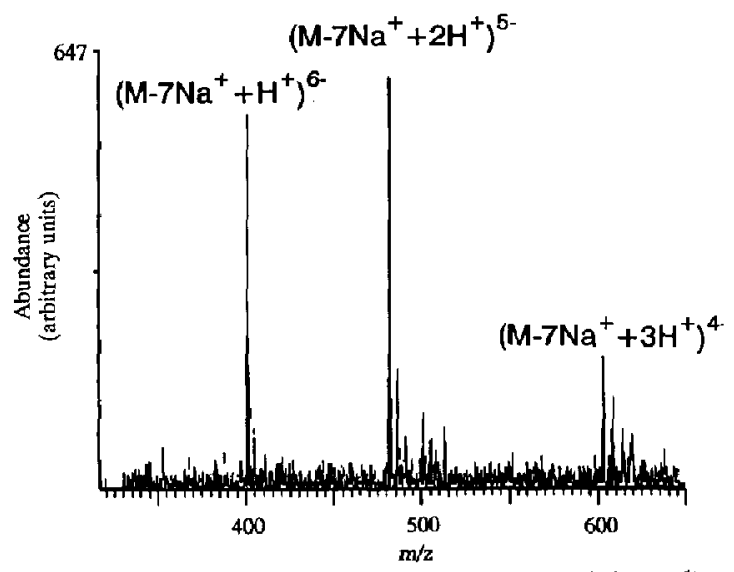

Figure 5. The negative ion ES mass spectrum of the sodium salt of $5^{\prime}$-d(GTGGCCAC)-3'.
CAC), provides an example typical of all three isomers. Depending upon conditions, the base peak in the spectra corresponded either to $\left(\mathrm{M}-7 \mathrm{Na}^{+}+\mathrm{H}^{+}\right)^{6-}$ $(m / z 400.5)$ or $\left(\mathrm{M}-7 \mathrm{Na}^{+}+2 \mathrm{H}^{+}\right)^{5-}(\mathrm{m} / \mathrm{z} 480.6)$. Tandem mass spectrometry data were acquired for both types of ions from each of the isomers and, in some cases, MS ${ }^{n}$ experiments were performed up to $n=4$. Under no conditions were ions with the maximum charge state, $\left(\mathrm{M}-7 \mathrm{Na}^{+}\right)^{7-}$, observed in abundance sufficient for $\mathrm{MS}^{n}$ experiments.

Perhaps the single most striking observation in the CID of all of the parent ions derived from the three isomers is the highly efficient loss of the adenine anion followed by cleavage of the $3^{\prime} \mathrm{C}-\mathrm{O}$ bond of the sugar from which the adenine anion had been lost. This sequential fragmentation to yield ( $\left.\mathrm{a}-\mathrm{B}_{n}(\mathrm{~A}){ }^{-}\right)$and $w$-type product ions occurred to some extent even at the lowest supplementary of amplitudes employed. At supplementary if amplitudes in excess of $1.5 \mathrm{~V}$ p-p the ion formed by loss of an adenine anion and which led to the $\left(a-B_{n}(A)\right)$ and w-type ions could barely be distinguished from the noise. This sequential fragmentation generally accounted for $90 \%$ or more of the total fragmentation. However, some minor decomposition channels could be observed, including a direct loss of a guanine anion from each isomer. These observations, and others, are illustrated below with selected MS/MS spectra of the anions derived from the isomeric octamers.

Figure 6a shows the MS/MS spectrum of the (M$\left.7 \mathrm{Na}^{+}+2 \mathrm{H}^{+}\right)^{5-}$ ion of $\mathrm{d}$ (CGGATCCG) acquired with a supplementary rf amplitude applied to the end caps of $1 \mathrm{~V}$ p-p. The most intense product ion is observed at $m / z 567.5$ and corresponds to the loss of an adenine anion which, in the case of this isomer, corresponds to $\left(\mathrm{M}-7 \mathrm{Na}^{+}+2 \mathrm{H}^{+}-\mathrm{B}_{4}(\mathrm{~A})^{-}\right)^{4-}$. [The ion at $\mathrm{m} / \mathrm{z}$ 485.2 is not a product ion but is the $\left(\mathrm{M}-6 \mathrm{Na}^{+}+\mathrm{H}^{+}\right)^{5-}$ ion which was not rejected in the mass selection process.] The complementary ion $\mathrm{B}_{4}(\mathrm{~A})^{-}$appears at $m / z$ 134. The three other major product ions in the spectrum are due to further fragmentation of the $\left(\mathrm{M}-7 \mathrm{Na}^{+}+2 \mathrm{H}^{+}-\mathrm{B}_{4}(\mathrm{~A})^{-}\right)^{4-}$ ion. Two of the ions are doubly charged and constitute the complementary pair $\left(a_{4}-B_{4}(A)^{-}\right)^{2-}$ and $w_{4}^{2-}$ (see Scheme IV). The third major product ion observed in the spectrum is also a member of a complementary pair, the presence of its mate being confirmed in an extended mass range experiment. This complementary pair was formed by cleavage at the same site but yielded an unsymmetrical charge distribution. These ions are $\left(a_{4}\right.$ $\left.B_{4}(A)^{-}\right)^{-}$and $w_{4}^{3-}$. The genealogy of this spectrum was confirmed with an $\mathrm{MS}^{3}$ experiment in which the first-generation product ion $\left(\mathrm{M}-7 \mathrm{Na}^{+}+2 \mathrm{H}^{+}\right.$. $\left.\mathrm{B}_{4}(\mathrm{~A})^{-}\right)^{4-}$ was isolated and subjected to $\mathrm{CID}$.

Figure $6 \mathrm{~b}$, which gives the MS/MS spectrum of the $\left(\mathrm{M}-7 \mathrm{Na}^{+}+\mathrm{H}^{+}\right)^{6-}$ ion also from d(CGGATCCG), again illustrates the strong tendency observed with all of the isomers for formation of $(a-B(A))$ and w-type anions. In this case, however, more complete dissoci- 

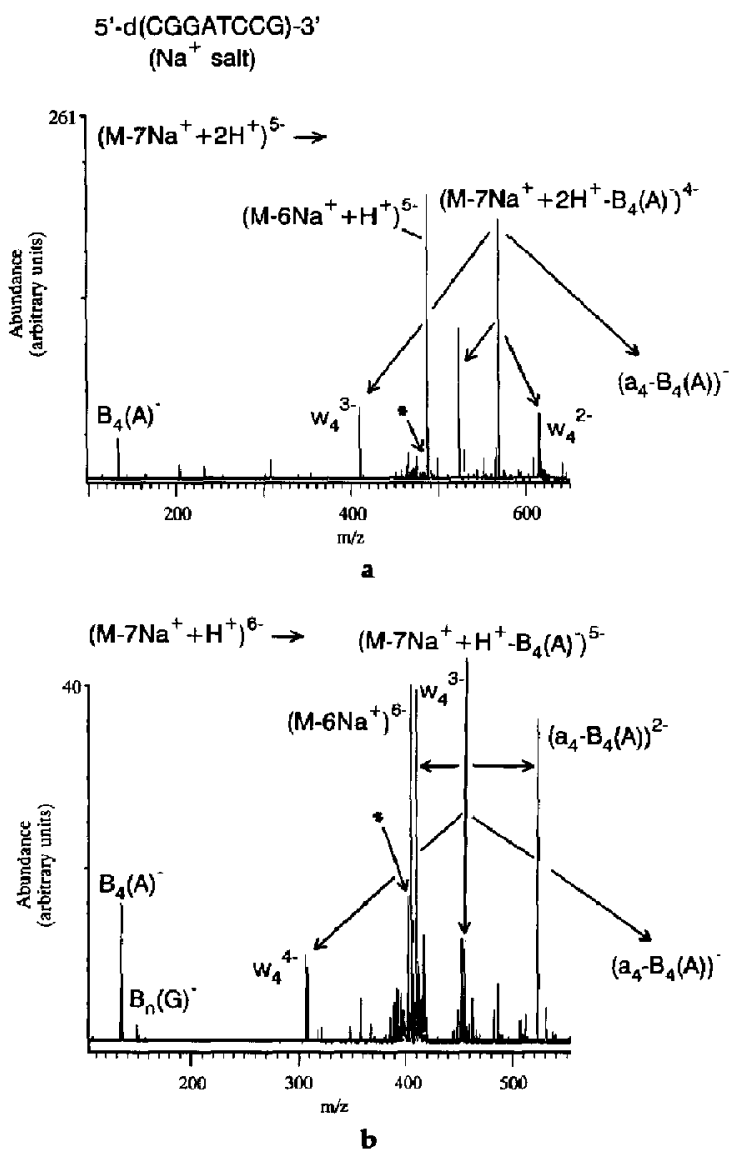

Figure 6. MS/MS spectra of the (a) $\left(\mathrm{M}-7 \mathrm{Na}^{+}+2 \mathrm{H}^{+}\right)^{5-}$ and (b)

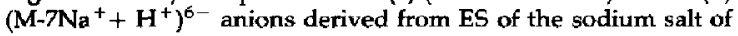
5 -d(CGGATCCG)-3'. The asterisk indicates the position of the parent ion.

ation of the first-generation product ion, $\left(\mathrm{M}-7 \mathrm{Na}^{+}+\right.$ $\left.\mathrm{H}^{+}-\mathrm{B}_{4}(\mathrm{~A})^{-}\right)^{5-}$, is observed. The same supplementary rf amplitude used to acquire the spectrum of Figure 6a was used here but the combination of a higher $q_{z}$ value during collisional activation combined with the expected lower ion stabilities owning to the higher coulombic field present in these ions may account for the increased degree of dissociation. Once again, two sets of complementary ions are formed from dissocia- tion of the ion formed by loss of the adenine anion. One set includes a triply charged anion, $\mathrm{w}_{4}^{3-}$, and a doubly charged ion, $\left(a_{4}-B_{4}(A)^{-}\right)^{2-}$, whereas the other set is composed of $\mathrm{w}_{4}^{4-}$ and its complement $\left(\mathrm{a}_{4-}\right.$ $\left.B_{4}(A)^{-}\right)^{-}$. The presence of the latter anion was confirmed in an extended mass range experiment. Interestingly, small signals for the guanine anion $(m / z 150)$ and its complementary ion were also observed in this spectrum as well as some of those derived from ions of other isomers (see below). This is a minor reaction channel relative to the loss of the adenine anion but may also lead to structurally informative consecutive dissociation. Unfortunately, the signal levels in these experiments were too low to investigate this reaction channel further by MS ${ }^{n}$.

Figures $7 \mathrm{a}$ and $8 \mathrm{a}$ give the MS/MS spectra of the $\left(\mathrm{M}-7 \mathrm{Na}^{+}+2 \mathrm{H}^{+}\right)^{5-}$ anions from d(GTGGCCAC) and d(GGACGTCC), respectively, and Figures $7 \mathrm{~b}$ and $8 \mathrm{~b}$ show the MS/MS spectra of the respective $\left(\mathrm{M}^{-7 \mathrm{Na}^{+}+}\right.$ $\left.\mathrm{H}^{+}\right)^{6-}$ anions. In all cases, the supplementary $\mathrm{rf}$ amplitude was adjusted to avoid complete fragmentation of the anion formed by loss of the adenine anion. The relevant figures indicate those cases in which a complementary ion of $m / z>650$ was formed, as confirmed by an extended mass range experiment. Schemes V and VI indicate the major ions observed. As with the other isomer, the loss of an adenine anion was observed to be, by far, the dominant dissociation channel. Relatively small signals were observed for the loss of a guanine anion. This channel appears to compete most effectively for the more highly charged parent ion, viz. $\left(\mathrm{M}-7 \mathrm{Na}^{+}+\mathrm{H}^{+}\right)^{6-}$, although too few data are available here to make a firm generalization. Further fragmentation of the multiply charged product anion formed by loss of the adenine anion occurs almost exclusively at the $3^{\prime} \mathrm{C}-\mathrm{O}$ bond of the sugar that lost the adenine anion.

Unfortunately, too few data are presently available on dissociations of both singly charged oligonucleotides and multiply charged oligonucleotides to draw general conclusions regarding their similarities and differences. However, a few consistent observations are noteworthy. For example, $\mathrm{B}^{-}$anions have also been observed in MS/MS spectra of singly charged oligonucleotide anions $[8,24,25]$. However, unlike the multiply charged anions studied here, singly charged oligonucleotide anions show a strong

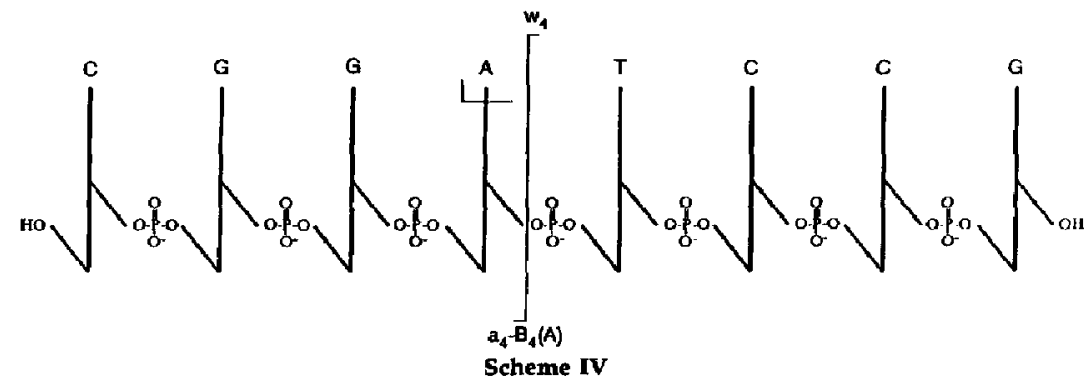




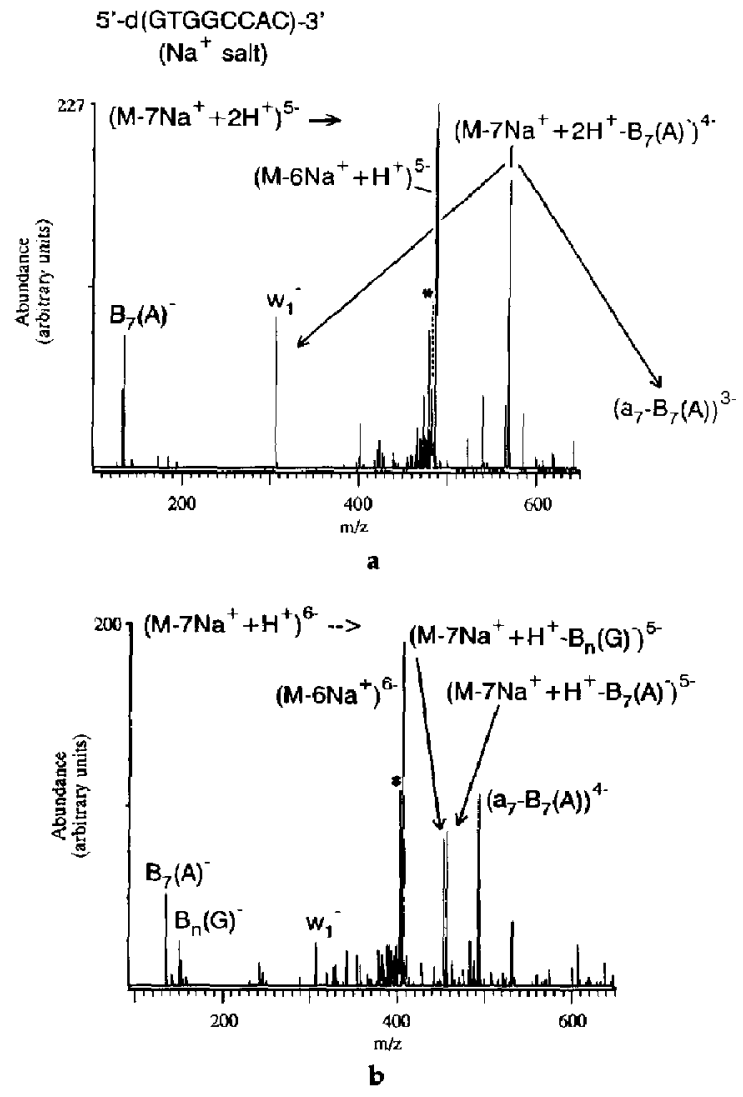

Figure 7. MS/MS spectra of the (a) $\left(\mathrm{M}-7 \mathrm{Na}^{+}+2 \mathrm{H}^{+}\right)^{5-}$ and (b) $\left(\mathrm{M}-7 \mathrm{Na}^{+}+\mathrm{H}^{+}\right)^{6-}$ anions derived from $\mathrm{ES}$ of the sodium salt of 5 -d(GTGGCCAC)-3'. The asterisk indicates the mass-to-charge ratio of the parent ion.

tendency for the loss of the neutral base (i.e., $\mathrm{AH}$, $\mathrm{CH}, \mathrm{GH}$, or $\mathrm{TH}$ ) at the $3^{\prime}$ end of the chain $[8,24,25]$. The location of the base appears to outweigh the importance of the identity of the base [25], in contrast to the strong tendency for the loss of $\mathrm{A}^{-}$regardless of location observed for the multiply charged anions. It is probably premature to speculate on these observations. Clearly, the coulombic field associated with the multiply charged ions can significantly affect bond strengths in the ion and the localization of charge. Furthermore, the multiply charged anions in this study were largely devoid of protons, which makes the loss of a neutral base statistically less likely. A systematic study of several model oligonucleotides as a function of charge state and, within each charge state, as a function of the number of protons versus sodium ions is clearly desirable to rationalize these interesting observations.

\section{Summary and Conclusions}

Much has yet to be learned about the behavior of multiply charged oligonucleotides under collisional

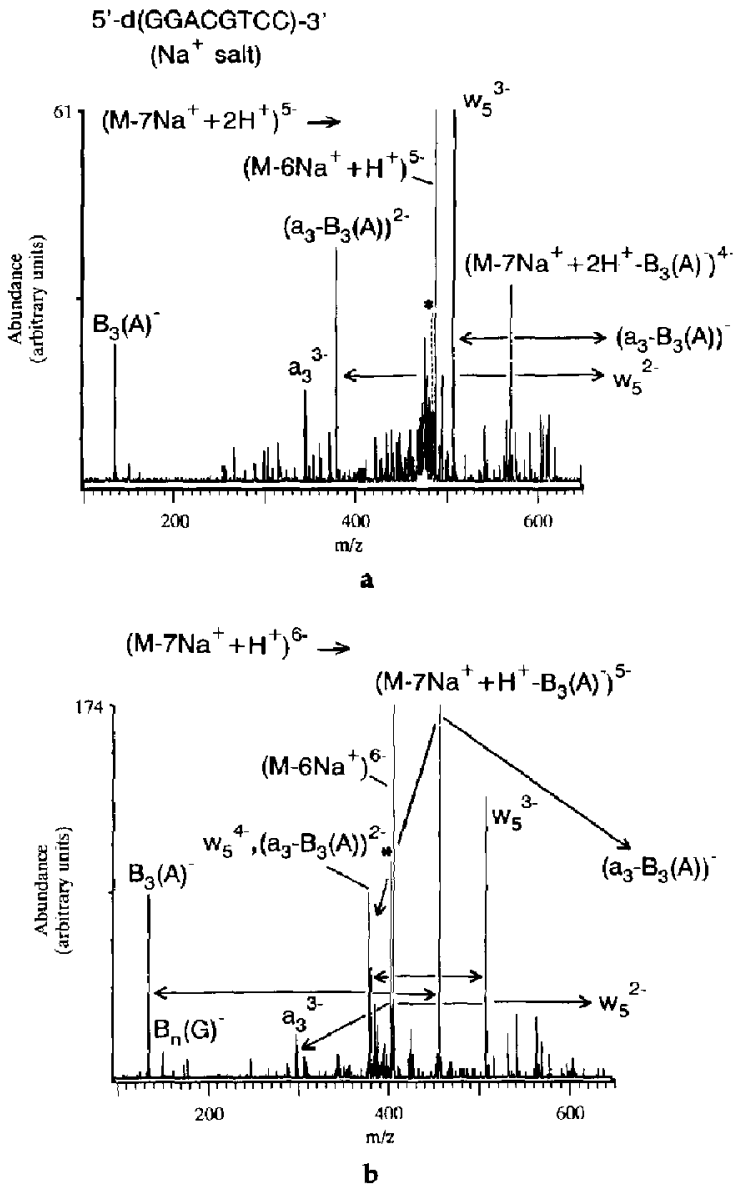

Figure 8. MS/MS spectra of the (a) $\left(\mathrm{M}-7 \mathrm{Na}^{+}+2 \mathrm{H}^{+}\right)^{5-}$ and (b) $\left(\mathrm{M}-7 \mathrm{Na}^{+}+\mathrm{H}^{+}\right)^{6-}$ anions derived from ES of the sodium salt of 5 '-d(GGACGTCC)-3'. The asterisk indicates the mass-to-charge ratio of the parent ion.

activation conditions. Nevertheless, these studies have revealed several important characteristics of small ( $n=4-8)$, multiply charged oligonucleotide anions. For example, they dissociate with high efficiency under quadrupole ion trap collisional activation conditions even at relatively low $q_{2}$ values. Complementary pairs of ions are generally apparent, provided collisional activation conditions are gentle enough to avoid subsequent fragmentation of one of the ions. The appearance of complementary ion pairs greatly simplifies spectral interpretation. There is a strong tendency for the loss of an adenine anion from adenosine-containing oligonucleotides and a relatively weak tendency for the loss of a guanine anion when both guanosine and adenosine are present. The product inns formed from the loss of the adenine anion tend to fragment at the $3^{\prime} \mathrm{C}-\mathrm{O}$ bond of the sugar from which the adenine group has been lost to form (a-B(A)) and $w$-type fragments. Various charge state distributions among the second-generation products are ob- 


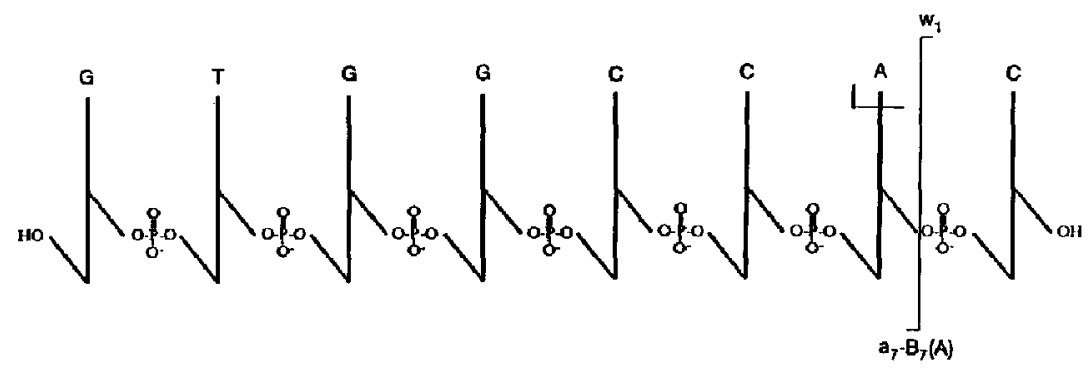

Scheme V

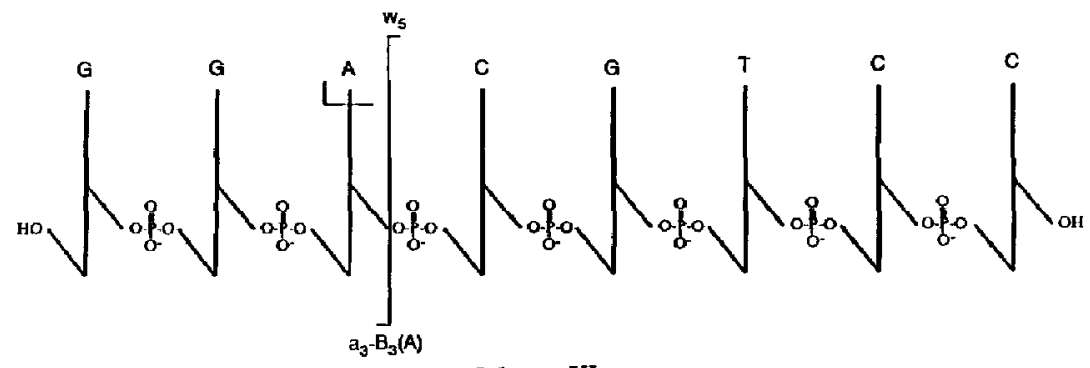

Scheme VI

served from this cleavage, which accounts for $>90 \%$ of the total loss of the second-generation parent ion. The sequence information available from the MS/MS and $\mathrm{MS}^{n}$ spectra of the octamers is far from complete. However, the high MS/MS efficiencies observed for these ions and the fact that most of the product ion signal is concentrated in a few structurally informative ions makes the prospects for the application of further stages of MS/MS particularly good [43]. Future studies will therefore be directed toward the application of MS $^{n}$ experiments to ions derived from more concentrated analyte solutions with possible extensions to larger oligomers.

\section{Acknowledgments}

This research was sponsored by the U.S. Department of Energy, Office of Basic Energy Sciences, under Contract DE-AC0584OR21400 with Martin Marietta Energy Systems, Inc.

\section{References}

1. McNeal, C. J.; Narang, S. A.; McFarlane, R. D.; Hsiung, H. M.; Brousseau, K. R. Proc. Natl. Acad. Sci. U.S.A. 1980, 77, 735.

2. McNeal, C. J. Nucl. Instrum. Methods 1982, 198, 139.

3. Viari, A.; Ballini, J.-P.; Vigny, P.; Shire, D.; Dousset, P. Biomed. Environ. Mass Spectrom. 1987, 14, 83.

4. Grotjahn, L. In Mass Spectrometry in Biomedical Research, Gaskell, S. J., Ed.; John Wiley \& Sons: New York, 1986; o 215.

5. Slowikowski, D. L.; Schram, K. H. Nucleosides Nucleotides 1985, 4, 309.

6. Budzikiewicz, H. Mass Spectrom. Rev. 1985, 4, 145.

7. Karas, M.; Hillenkamp, F. Anal. Chem. 1988, 60, 2299.

8. Hettich, R.; Buchanan, M. J. Am. Soc. Mass Spectrom., in press.
9. Spengler, B.; Pan, Y.; Cotter, R. J. In Proceedings of the 38th ASMS Conference on Mass Spectrometry and Altied Topics, Tucson, $\mathrm{AZ}_{\text {, }}$ 1991, p 164.

10. Wong, S. F.; Meng, C. K.; Fenn, J. B. I. Phys. Chem. 1988, $92,546$.

11. Meng, C. K.; Mann, M.; Fenn, J. B. Z. Phys. D 1988, 10, 361.

12. Mann, M.; Meng, C. K; Fenn, J. B. In Proceedings of the 36th Annual Conference on Mass Spectrometry and Allied Topics, San Francisco, CA, June 1988, p 1207.

13. Fenn, J. B.; Mann, M.; Meng, C. K.; Wong, S. F.; Whitehouse, C. M. Science (Washington, DC) 1989, 246, 64.

14. Fenn, J. B.; Mann, M.; Meng, C. K.; Wong, S. F.; Whitehouse, C. M. Mass Spectrom. Rev. 1990, 9, 37.

15. Smith, R. D.; Loo, J. A., Edmonds, C. G.; Barinaga, C. J.; Udseth, H. R. Anal. Chem. 1990, 62, 882.

16. Huang, E. C.; Wachs, T.; Conboy, J. J.; Henion, J. D. Anal. Chem. 1990, 62, 713A.

17. Mann, M. Org. Mass Spectrom. 1990, 25, 575.

18. Mann, M.; Meng, C. K.; Fern, J. B. Anal. Chem. 1989, 61, 1702.

19. Covey, T. R.; Bonner, R. F.; Shushan, B. I.; Henion, J. Rapid Comm. Mass Spectrom. 1988, 2, 249.

20. Edmonds, C. G.; Barinaga, C. J.; Loo, J. A.; Udseth, H. R.; Smith, R. D. In Proceedings of the 37th ASMS Conference on Mass Spectrometry and Allied Topics, Miami Beach, FL, 1989, p 844.

21. Henry, K. D.; McLafferty, F. W. Org. Mass Spectrom. 1990, 25,490 .

22. Schwartz, J. C.; Syka, J. E. P.; Jardine, I. J. Am. Soc. Mass Spectrom. 1991, 2, 198.

23. McLuckey, S. A.; Glish, G. L.; Van Berkel, G. J. Anal. Chem., manuscript submitted for publication.

24. Cerny, R. L.; Tomer, K. B.; Gross, M. L; Grotjahn, L. Anal. Biochem. 1987, 165, 175.

25. Cerny, R. L.; Gross, M. L.; Grotjahn, L. Anal. Biochem. 1986, $156,424$.

26. Sidona, G.; Uccella, N.; Weclawek, K. J. Chem. Res. (Suppl.), 1982, 184. 
27. Panico, M.; Sidona, G.; Uccella, N. J. Am. Chem. Soc. 1983, $105,5607$.

28. Neri, N.; Sidona, G.; Uccella, N. Gazz. Chim. Ital. 1983, 113, 197.

29. Crow, F. W.; Tomer, K. B.; Gross, M. L.; MeCloskey, J. A.; Bergstrom, D. E. Anal. Biochem. 1984, 139, 243.

30. Isern-Flecha, I.; Jiang, X.-Y.; Cooks, R. G.; Pfleiderer, W.; Chae, W.-G.; Chang, C.-J. Biomed. Environ. Mass Spectrom. 1987, 14,17

31. Plaziak, A. S.; Costello, C. E.; Comess, K. M.; Bancroft, D. P.; Lippard, S. J. In Proceedings of the 38th ASMS Conference on Mass Spectrometry and Allied Topics, Tucson, AZ, 1990. p 792 .

32. McLuckey, S. A.; Glish, G. L.; Asano, K. G. Anal, Chim. Acta 1989, 225, 25.

33. Van Berkel, G. J.; Glish, G. L.; McLuckey, S. A. Aral. Chem. 1990, 62, 1284.

34. McLuckey, S. A.; Van Berkel, G. J.; Glish, G. L.; Huang, E. C.; Henion, J. D. Anal Chem. 1991, 63, 375.
35. McLuckey, S. A.; Glish, G. L.; Asano, K. G.; Grant, B. C. Anal. Chem. 1988, 60, 2220.

36. Stafford, G. C.; Kelley, P. E.; Syka, J. E. P.; Reynolds, W. E.; Todd, J. F. J. Int. J, Mass Spectrom. Ion Processes, 1984, 60, 85.

37. Kaiser, R. E., Jr.; Cooks, R. G.; Moss, J,; Hemberger, P. H. Rapid Commun. Mass Spectrom. 1989, 3, 50.

38. Kaiser, R. E., Jr., Louris, J. N.; Amy, J. W.; Cooks, R. G. Rapid Commun. Mass Spectrom. 1990, 3, 225.

39. McLuckey, S. A.; Goeringer, D. E.; Glish, G. L. J Am. Soc. Mass Spectrom, 1991, 2, 11

40. Louris, J. N.; Cooks, R. G.; Syka, J. E. P.; Kelley, P. E.; Stafford, G. C.; Todd, J. F. J. Anal. Chem. 1987, 59, 1677.

41. March, R. E.; Hughes, R. J. Quadrupole Ion Storage Mass Spectrometry, John Wiley \& Sons: New York, 1989.

42. Roepstorff, P.; Fohlman, J. Biomed. Mass Spectrom. 1984, 11, 601.

43. McLuckey, S. A.; Glish, G. L.; Van Berkel, G. J. Int. J. Mass Spectrom. Ion Processes, 1991, 106, 213. 